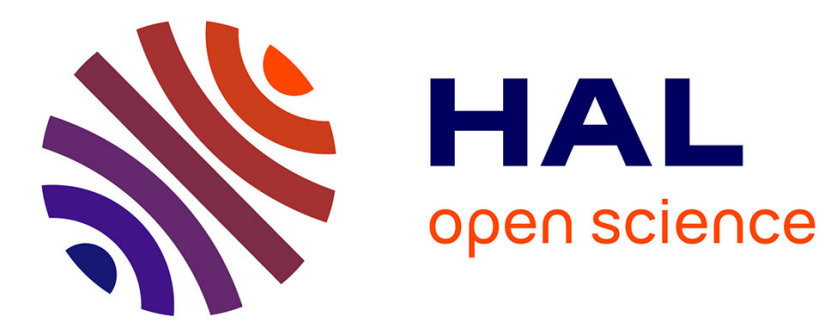

\title{
Preliminary study on the modelling of negative leader discharges
}

L Arevalo, V Cooray

\section{To cite this version:}

L Arevalo, V Cooray. Preliminary study on the modelling of negative leader discharges. Journal of Physics D: Applied Physics, 2011, 44 (31), pp.315204. 10.1088/0022-3727/44/31/315204 . hal00642366

\section{HAL Id: hal-00642366 https://hal.science/hal-00642366}

Submitted on 18 Nov 2011

HAL is a multi-disciplinary open access archive for the deposit and dissemination of scientific research documents, whether they are published or not. The documents may come from teaching and research institutions in France or abroad, or from public or private research centers.
L'archive ouverte pluridisciplinaire HAL, est destinée au dépôt et à la diffusion de documents scientifiques de niveau recherche, publiés ou non, émanant des établissements d'enseignement et de recherche français ou étrangers, des laboratoires publics ou privés. 


\title{
Preliminary study on the modeling of negative leader discharges
}

\author{
L Arevalo and V Cooray \\ Uppsala University, Lightning Research Group, Sweden \\ E-mail:Liliana.Arevalo@ angstrom.uu.se
}

\begin{abstract}
Nowadays, there is great interest in understanding the physics underlying positive and negative discharges because of the importance of improving lightning protection systems and of coordinating the insulation for high voltages. Numerical simulations of positive switching impulses made in long spark gaps in a laboratory are achievable because the physics of the process is reasonably well understood and because of the availability of powerful computational methods. However, the existing work on the simulation of negative switching discharges has been held up by a lack of experimental data and the absence of a full understanding of the physics involved. In the scientific community, it is well known that most of the lightning discharges that occur in nature are of negative polarity, and because of their complexity, the only way to understand them is to generate the discharges in laboratories under controlled conditions.
\end{abstract}

The voltage impulse waveshape used in laboratories is a negative switching impulse. With the aim of applying the available information to a self-consistent physical method, an electrostatic approximation of the negative leader discharge process is presented here. The simulation procedure takes into consideration the physics of positive and negative discharges, considering the negative leader to be propagating towards a grounded electrode and the positive leader to be propagating towards a rod electrode. The simulation considers the leader channel to be thermodynamic, and assumes that the conditions required to generate a thermal channel are the same for positive and negative leaders. However, the magnitude of the electrical charge necessary to reproduce their propagation and thermalization is different, and both values are based on experimental data. The positive and negative streamer development is based on the constant electric field characteristics of these discharges, as found during experimental measurements made by different authors. As a computational tool, a finite element method based software was employed. The simulations are compared with experimental data available in the literature.

\section{Introduction}

A great deal of scientific work has been dedicated to the study of discharges in long spark gaps under different voltage stresses and polarities with the aim of understanding the physics of the discharge and of being able to predict the behavior of natural discharges like the lightning discharge. These experimental studies have been used to develop empirical and physical models capable of assisting in the design of protection systems against lightning, of the insulation coordination and of protecting high voltage electrical equipment in general.
However, because of the complexity of the negative discharge, most of the modeling work has been dedicated to positive discharges. In nature, most of the lightning discharges are of negative polarity. Given this, the development of numerical models capable of reproducing negative discharges will improve the design of protection systems and the design of equipment that can withstand overvoltages originating from direct and/or indirect strikes.

The first step towards attaining the goal of modeling negative lightning discharges, is to model laboratory gap discharges developed in a controlled 
environment, such as laboratory discharges produced under switching impulses. Thus, the research presented in this contribution represents an effort to reproduce discharges in long laboratory spark gaps under different kinds of switching impulses.

The first lightning attachment model incorporating assessments of real physical parameters was proposed by Dellera and Garbagnati [1]. This model, called the leader progression model, includes a simulation of the propagation of both negative and positive leaders achieved using electrostatic considerations. Later, a model that simulates positive leader channels, and which incorporated more of the physics of the discharge, was constructed by Rizk [2, 3]. Then, based on Les Renardieres' experimental work $[4,5]$, which gave a clear description of the leader behavior under laboratory conditions, Gallimberti [6] developed the physics pertinent to understanding the development of leaders. Subsequently, Gallimberti and Bondiou [7] built up a physical methodology that simulates positive upward leaders under switching impulses. Based on the work of Bondiou and Gallimberti [7], Becerra and Cooray [8] developed a model to study the attachment of lightning flashes to grounded structures. However, none of the researchers investigating this, namely, Dellera and Garbagnati [1], Rizk [2,3] and Becerra and Cooray [8] modeled the negative stepped leader from first principles.

In 1994, Bacchiega et al [9] developed the first theoretical model of the propagation of a negative stepped leader across long air gaps. By 1998, Castellani et al [10] had conducted experimental measurements in such long gaps to identify the bileader process, and thereby providing a great amount of detail on the negative leader development.

In 2000, Mazur et al [11] presented results of a physical model of negative leaders under the effect of a downward-coming positive leader. In 2002, Gallimberti and Lalande et al [12, 13] presented a bipolar model to reproduce triggered lightning, in which they included positive and negative lightning based on the measurements of Les Renardieres [5] and Castellani [10] and the model of Bacchiega [9].
The other available models are stochastical that make use of fractals, and the electrical breakdown models of Niemeyer et al. [14], Tsonis and Elsnet [15], and Sanudo et al. [16], and some of them use the electrical characteristics of the leader channel published by Petrova [17]. The latest available model by Beroual et al $[18,19]$ that calculates the evolution of a lightning discharge is based on electrical network parameters derived from electromagnetism, wave propagation and gas discharge theory.

All of the above-mentioned models are approximations, however, which, in one way or other, cannot reproduce all the different stages of the negative discharge. Thus, to reproduce processes such as the relaxation time or the positive leader propagation or space leader, they tune parameters or assume circuital arrangements.

Here, a new physical model is proposed based on the stages and characteristic measurements identified by Castellani [10] and the subsequent phases of the physics of the negative discharge identified and used by Castellani, Mazur and their co-workers $[10,11,12]$. The methodology considers processes such as the negative leader channel, composed of negative and positive streamers and the negative leader stem. For the positive and negative streamers, we used the streamer criterion of Gallimberti [6].

Once the first corona has been incepted, the charge in the streamer zone is calculated, assuming that the streamer zone is characterized by a minimum propagation electric field of $450 \mathrm{kV} / \mathrm{m}$ and $750 \mathrm{kV} / \mathrm{m}$ for positive and negative corona, respectively $[6,7,10,13]$.

The voltage drop in the leader channels is evaluated using the "local thermodynamic equilibrium" (LTE) equations of Gallimberti [6]. Once the radius of the leader channel has been given as an input parameter, reported values from experimental measurements [4], the equations can predict the development of the electric field inside the leader channel. 


\section{Physical processes underlying the negative discharge}

The evolution of a negative discharge is determined by environmental conditions, like the humidity, temperature and pressure, and by the electric field characteristics. The physical description of the negative discharge assumed here is based on the characteristics presented by Castellani [10], Les Renardieres 1978 [5], Lalande 2002 [12] and Gallimberti et al [13]. This description corresponds to observations of experiments performed in a rod-plane arrangement to avoid interaction between positive and negative discharges. The stimuli used to analyze the electrical discharge were switching impulses, with different front and tail times and peak magnitudes. The electrical response of these configurations under negative polarity is of great interest from an engineering point of view because the majority of stresses caused by lightning in electrical networks are of negative polarity, and even when they do not dominate the breakdown process, they can play a significant role in multielectrode and phase-to-phase arrangements. Furthermore, the study of negative discharges will improve the knowledge of the lightning mechanism, which might help to clarify shielding problems and predict outage rates of power lines.

The first phenomenon involved in a negative discharge is the formation of a negative streamer corona (NC) at time $t_{i}$. Then, after at time $t_{l}$, a discharge process called a "pilot" appears (PL), in which the simultaneous development of a positive streamer propagating towards the cathode and a negative streamer propagating towards the anode occurs.

At a time $t_{2}$, a space leader (SL) develops from a space stem, and at $t_{3}$, the conditions are suitable for a negative leader (NL) to propagate towards the anode. On the basis of the published results [7, 13], one can conclude that the thermodynamic conditions for the formation of positive leaders ought to be very similar to those for negative leaders.

At time $t_{4}$, a stem is formed in the space where the two pilots are located. However, this stage is not observed for gaps of less than $4 \mathrm{~m}[5,10]$. From this stem, a negative streamer and a leader crossing the space (SL) are formed. The leader possesses two heads, one of which is a positive leader and propagates towards the cathode, the other being a negative leader that propagates towards the anode.

When the space leader reaches the negative electrode, a negative corona is formed and the leader channel is illuminated brightly. This step is called a step discharge. Briefly, the negative discharge propagates discontinuously, hence the name, and with complex processes taking place between the negative and positive streamers. Figure 1 was adapted from [13] to illustrate the various stages of a negative discharge.

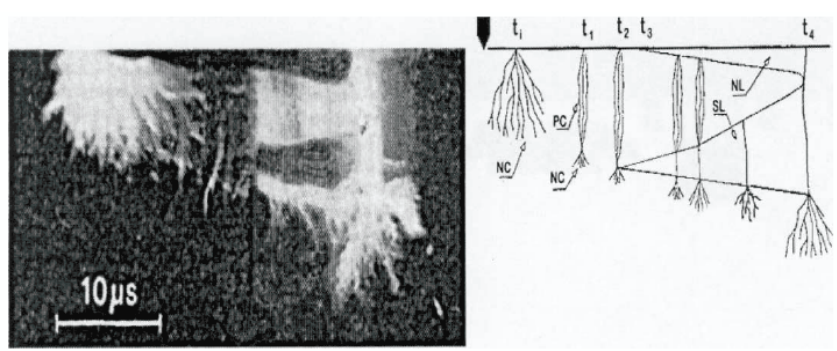

Figure 1. Negative leader development process. This figure has been reproduced from a manuscript by Gallimberti [13] with the permission of Elsevier.

\section{The principles of the model}

\subsection{The methodology}

The complexity of the electric field calculations and the need to implement all the different physical equations required made it necessary to employ software for a finite element method. The calculation procedure was divided up into a number of different physical stages as follows:

\subsubsection{The negative streamer region}

First, the background electric field was calculated for the applied switching impulse voltage source to find out the voltage level of the source at which the streamer inception criterion is satisfied.

$$
\exp \left[\int_{\Delta x}(\alpha-\eta) \cdot d x\right] \geq N_{\text {stab }}
$$


where $\alpha$ is the first ionization coefficient, $\eta$ is the attachment coefficient and $\Delta x$ is the size of the active region where $(\alpha-\eta)>0$ and $N_{\text {stab }}$ is the minimum charge that produces a space charge field high enough to reproduce the streamer tip. The ionization and attachment coefficients are calculated as a function of the local fields.

For the calculation of the streamer region, the methodology presented in [20] is used. The calculation of the streamer zone divides up naturally into four main stages:

1. As the streamer region is characterized for an almost constant electric field between 700 $1000 \mathrm{kV} / \mathrm{m}[6,7,10,13]$, the volumetric region between the tip of the leader channel/or the high voltage electrode and the ground point is divided into several layers. For each layer, the area where the field is equal to or higher than the stabilization electric field (of $750 \mathrm{kV} / \mathrm{m}$ ) is identified.

2. In this streamer region, it is assumed that the streamers propagate along the electric field lines and that the drop in the potential along the electric field line to the boundary of the region is equal to $750 \mathrm{kV} / \mathrm{m}$.

3. The streamer region is then divided into several layers and the charge is calculated for each layer. This calculation requires that the direction of the electric field vector be taken into consideration, including the direction at the edge of the region, as illustrated in Figure 2.

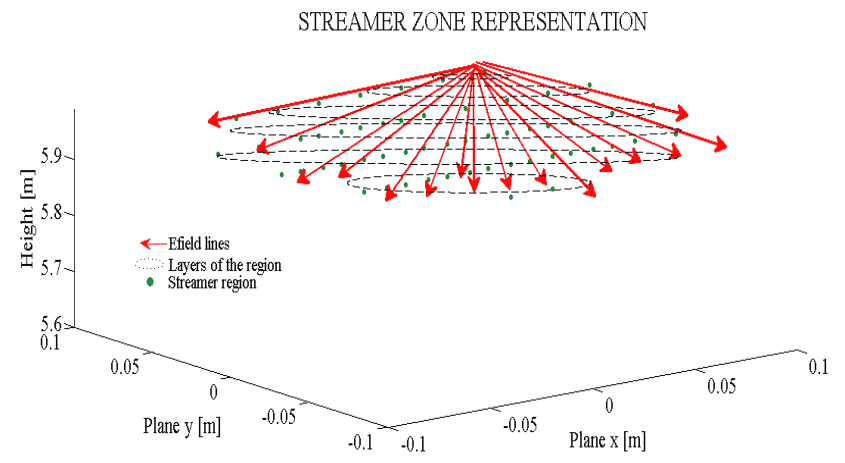

Figure 2. Delimitation of the streamer region the arrows indicate the direction of the electric field, which is also the direction of propagation of the streamers
4. Using Gauss's theorem, the streamer charge located in each layer $Q_{i}$ is calculated, and the total charge accumulated in the volume for each time step $Q_{\text {total }}$ is computed.

$$
\begin{aligned}
& Q_{i}=\iint_{s} \varepsilon_{0} \cdot \vec{E} \cdot d \vec{S} \\
& \Delta Q_{\text {total }}=\sum_{i=1}^{n} Q_{i}
\end{aligned}
$$

Then the negative streamer charge is calculated, using Equations (2) and (3), where $\varepsilon_{0}$ is the permittivity of the air, $\boldsymbol{E}$ corresponds to the electric field vector and $S$ is the vector of the surface over which the integration is performed.

The next stage in the discharge process is the socalled "pilot system", and the calculation for this is made as follows.

\subsubsection{The "Pilot Streamer System"}

Even though, there is no clear explanation of the physics underlying the discharge process because of its complexity and the lack of experimental data, some experimental results have indicated that each pilot streamer discharge starts at the lower tip of the preceding one and that this form of initiation is associated with every current pulse $[5,10]$. A consistent explanation was, however, proposed by Bacchiega [9].

For the calculation of the potential profile and the reproduction of a pilot system, the following assumptions should be made:

1. It has been stated in the literature that the electric field necessary for the propagation of a negative streamer is almost constant and has a value of $750 \mathrm{kV} / \mathrm{m}$ [6]. Thus, the region in front of the tip that fulfils this electric field criterion has been identified, and the maximum axial length of the region has been calculated (see Figure 2).

2. Once the negative streamer is formed, a positive leader discharge will develop in the direction of the high voltage electrode. The simulation of this leader follows the methodology presented in the literature [2123]. The inception and the location of the 
propagation of this leader is assumed to be at the central axis of the arrangement and, as mentioned, it propagates towards the high voltage electrode.

3. Laboratory measurements made by Les Renardieres' Group have shown that, before the formation of the first pilot system, there is an enhancement of the electric field between the negative streamer and the grounded electrode, as a result of this, the electric field in the local region close to the tip of the negative streamer has a magnitude of $1 \cdot 10^{6} \mathrm{~V} / \mathrm{m} \mathrm{[2].} \mathrm{The} \mathrm{existence} \mathrm{of} \mathrm{this}$ electric field and the requirement that a positive discharge can propagate towards the high voltage electrode makes it necessary to assume that, from the tip of the negative streamer region, a first stem leader develops towards the high voltage electrode with an electric field magnitude of $1 \cdot 10^{6} \mathrm{~V} / \mathrm{m}$. In front of this stem leader, a positive streamer is located.

4. For the simulation of the positive and negative leader channel, Gallimberti's LTE equation is used [6].

The leader is decomposed into elementary segments with length $d l$, temperature $T$, pressure $P$ and a molecular density $n$ that is assumed to be uniform along the channel. The potential drop $\Delta U_{L}$ in the segment $i$ will then be: $\Delta U_{L i}=E_{L i} \cdot d l_{i}$ where $d l i$ is the length of the segment $i$ and $E_{L i}$ is the potential gradient of the segment of length $i$.

Gallimberti's model gives the evolution of the internal electric field $E_{L}$ as a function of the injected current, supposing that the conductivity of the leader channel is essentially controlled by electronic collisions between neutral molecules and accelerated electrons in the electric field $E_{L}$.

This estimation supposes that all the injected current $I_{L}$ is used to dilate the leader, and that the mass remains constant as the expansion takes place. The formulation describing this hypothesis results in the following set of equations:

$$
\pi \cdot a_{0 i}^{2} \cdot n_{0 i} \cdot d l_{i}=\pi \cdot a_{i}^{2} \cdot n_{i} \cdot d l_{i}
$$

$$
\frac{\gamma \cdot p_{0}}{\gamma-1} \cdot \frac{d\left(\pi \cdot a^{2}\right)}{d t}=E_{L} \cdot I_{L}
$$

where $a_{i}$ is the radius of the leader segment at a defined instant in time, $n_{i}$ is the neutral molecules' density at the same time, and $a_{0 i}$ and $n_{0 i}$ are the initial conditions for the leader formation. $P_{0}$ is the atmospheric pressure, $\gamma$ is the ratio between the specific heat at constant pressure and the volume constant, $\mathrm{d}\left(\pi a^{2}\right)$ is the variation in the crosssectional area of the leader, and $E_{L} I_{L}$ is the power injected into the channel during the time step, $d t$.

From equation (5), it is possible to calculate the channel section for the next time step from the function by considering the function at the time $t$, and the internal electric field and the charge $I_{L} d t$.

$$
\pi \cdot a^{2} \cdot(t+d t)=\pi \cdot a^{2}(t)+\frac{\gamma-1}{\gamma \cdot p_{0}} E_{L} \cdot I_{L} \cdot d t
$$

As the mass is constant, the molecules' density enables us to write:

$$
n(t+d t)=n(t) \frac{\pi \cdot a^{2}(t)}{\pi \cdot a^{2}(t+d t)}
$$

And, using the hypothesis that $E_{L} / n$ is constant, the internal electric field at that time will be equal to:

$$
E_{L}(t+d t)=\frac{n(t+d t)}{n(t)} E_{L}(t)
$$

From this it is possible to calculate the time evolution of the internal electric field for each segment and the potential drop along the leader channel:

$$
\Delta U_{L}=\sum_{i=1}^{k} E_{L i} \cdot d l_{i}
$$

where $k$ is the total number of segments.

Assuming that a first leader segment is incepted and that its initial characteristics are given by the parameters described in table 1, the electric field calculation is performed using finite element methods. In 
front of this leader channel, a positive streamer region is located, as presented in figure 3.

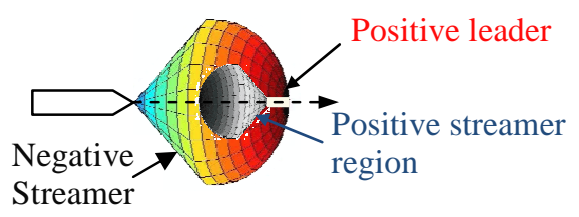

Figure 3. Illustration of the initial propagation of the pilot system. Note that it is assumed that the positive leader discharge is propagating along the main axis of the electrode arrangement.

5. To consider the positive streamer region, the region that satisfies the condition for a stable positive streamer of $450 \mathrm{kV} / \mathrm{m}$, close to the high voltage electrode is determined using the same methodology described to calculate the negative streamer region in section 3.1.1, using equations (2) and (3). For major details, please refer to the reference [20].

The potential distribution of every pilot streamer discharge is composed of a series of potential drops over: the positive streamer region, the positive leader channel and the negative streamer region located in front of the grounded electrode.

Several different phenomena need to be considered, including: the positive leader channel, the positive and the negative streamers. The relative impact of the different phenomena gives the total charge, which leads to the characteristic pulsing of the pilot system, defined by the so-called "relaxation time", which has been tuned to RLC electrical circuits in other models.

The electrical charge per unit length that is required to sustain the progression of the pilot streamer discharge was assumed to be $13.8 \mu \mathrm{C} / \mathrm{m}$, as Castellani estimated in [10]. In Figure 4, one can observe the potential profile distribution before and after the streamer development, and after the formation of the first pilot streamer discharge.

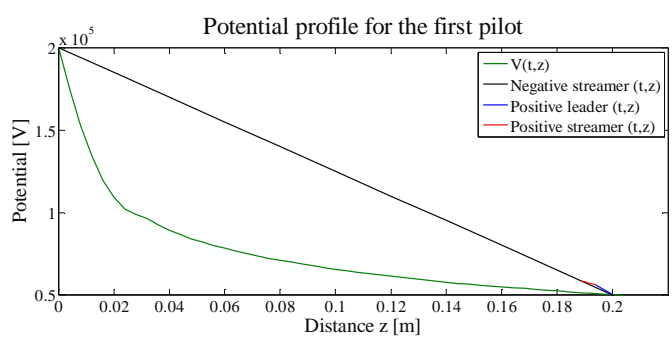

(a)

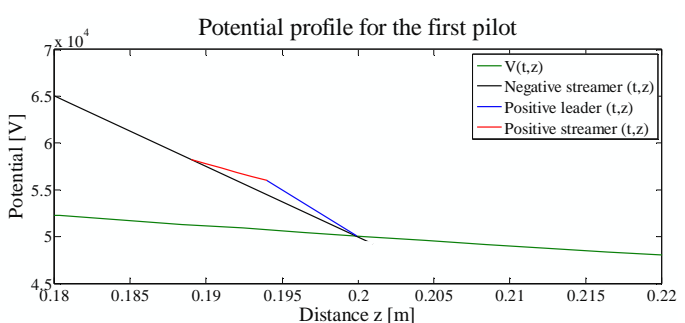

(b)

Figure 4. Potential distribution before and after the negative streamer development and after the formation of the first pilot streamer discharge.

Figure (a) is an overall view and (b) an enlargement of the potential incepted leader and the streamer channel.

The advance of the pilot is calculated from the minimum electrical charge per unit length required to sustain the pilot and the charge in the streamer region using equations (10) and (11). The advance of the positive leader $\Delta l_{L}^{(\mathrm{i})}$ can be determined by integrating the velocity of the leader, which is described in equation (10); where $\Delta Q_{\text {total }}$ is the corresponding total charge of the pilot system, $q_{L}$ is the charge per unit length required to sustain a pilot system, $\Delta L(t+d t)$ is the length of the next leader segment and $\mathrm{L}_{\mathrm{L}}(\mathrm{t})$ is the length of the present leader segment.

$$
\begin{aligned}
& \Delta l_{L}^{(i)}=\frac{\Delta Q_{\text {total }}^{(i)}}{q_{L}} \\
& \Delta L(t+d t)=L_{L}(t)+\Delta l_{l}
\end{aligned}
$$

\subsection{3 "Negative Leader Phase"}

The measured results extracted from the literature $[5,10]$ reveal that the charge necessary to incept a 
leader channel is of the order of $5.4 \mu \mathrm{C}$. This value is used in the present calculation to initiate the simulation of the leader stage. This charge includes all of the charge associated with the different streamers and the pilot systems developed up to the inception of the leader.

We assumed that the inception mechanism for the negative leader is similar to the one for the positive leader [21, 23]. This assumption is valid because the threshold electrical charge corresponds to the charge necessary to heat the "stem" to a critical temperature, which will lead to the formation of the first section of the leader channel. This negative leader is calculated using the thermo-equilibrium equations of Gallimberti [6], described in equations (4) to (9). The potential gradient immediately before a new leader segment is created is assumed to be 7.5 x $10^{5} \mathrm{~V} / \mathrm{m}$, from experimental evidence $[6,7,10$, $13]$.

The first incepted negative leader is assumed to propagate from the tip of the high voltage electrode to the tip of the negative streamer region, as presented in figure 5 .

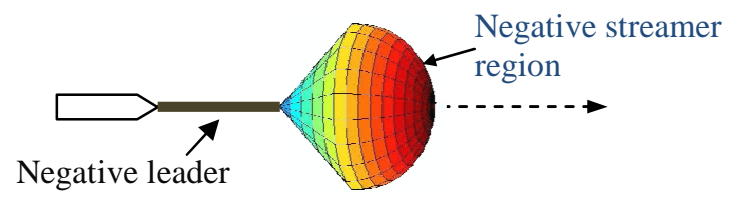

Figure 5. Illustration of the initial propagation of the negative leader. Note that it is assumed that the negative leader is propagating straight along the main axis of the electrode arrangement.

For the next stages of the simulation of the advancement of the negative leader, equations (10) and (11) are used and the charge per unit length required to sustain the negative leader propagation, $q_{L}$, was $108 \mu \mathrm{C} / \mathrm{m}$ based on the values published in the literature [10].

The new negative streamer region is found in front of this negative leader, then a new pilot system is calculated.

Table I. Input parameters used for the calculation of the negative leader discharge based on measurements made by Castellani and coworkers [10]

\begin{tabular}{|c|c|c|c|}
\hline Process & $\begin{array}{l}\text { Condition } \\
\end{array}$ & Magnitude & Ref. \\
\hline $\begin{array}{c}\text { Positive } \\
\text { Electric Field }\end{array}$ & $\begin{array}{c}\text { Positive streamer } \\
\text { Stabilization electric field }\end{array}$ & $450 \mathrm{kV} / \mathrm{m}$ & {$[6]$} \\
\hline $\begin{array}{c}\text { Negative } \\
\text { Electric Field }\end{array}$ & $\begin{array}{c}\text { Negative streamer } \\
\text { stabilization electric field }\end{array}$ & $750 \mathrm{kV} / \mathrm{m}$ & {$[6]$} \\
\hline $\begin{array}{l}\text { Initial channel } \\
\text { radius of a } \\
\text { newly created } \\
\text { leader segment }\end{array}$ & $\begin{array}{c}\text { Positive and negative } \\
\text { leader }\end{array}$ & $1 \cdot 10^{-3} \mathrm{~m}$ & [6] \\
\hline \multirow{2}{*}{$\begin{array}{c}\text { Pilot } \\
\text { progression }\end{array}$} & $\begin{array}{l}\text { Charge contained in the } \\
\text { first pilot }\end{array}$ & $0.5 \mu \mathrm{C}$ & {$[10]$} \\
\hline & $\begin{array}{l}\text { Charge per unit length } \\
\text { required to sustain the PC }\end{array}$ & $13.8 \mu \mathrm{C} / \mathrm{m}$ & {$[10]$} \\
\hline Space leader & $\begin{array}{l}\text { Minimum charge per unit } \\
\text { length required to incept a } \\
\text { space leader }\end{array}$ & $53.1 \mu \mathrm{C} / \mathrm{m}$ & {$[10]$} \\
\hline \multirow{4}{*}{$\begin{array}{c}\text { Negative } \\
\text { Leader Phase }\end{array}$} & $\begin{array}{c}\text { Charge required to incept a } \\
\text { negative leader }\end{array}$ & $5.4 \mu \mathrm{C}$ & {$[10]$} \\
\hline & $\begin{array}{l}\text { Charge required to sustain } \\
\text { the negative leader }\end{array}$ & $108 \mu \mathrm{C} / \mathrm{m}$ & {$[10]$} \\
\hline & $\begin{array}{l}\text { Potential gradient before a } \\
\text { new leader segment is } \\
\text { created }\end{array}$ & $750 \mathrm{kV} / \mathrm{m}$ & {$[6]$} \\
\hline & Initial length of the leader & $2 \times 10^{-2} \mathrm{~m}$ & {$[6]$} \\
\hline \multirow{3}{*}{$\begin{array}{c}\text { Positive } \\
\text { Leader Phase }\end{array}$} & $\begin{array}{l}\text { Charge required to sustain } \\
\text { a positive leader channel }\end{array}$ & $40-55 \mu \mathrm{C} / \mathrm{m}$ & [4] \\
\hline & $\begin{array}{l}\text { Potential gradient before a } \\
\text { new leader segment is } \\
\text { created }\end{array}$ & $450 \mathrm{kV} / \mathrm{m}$ & {$[6]$} \\
\hline & Initial length of the leader & $2 \times 10^{-2} \mathrm{~m}$ & {$[6]$} \\
\hline
\end{tabular}

\section{Application of the methodology}

Two different rod-plane configurations were tested with different switching impulses and gap distances to check the validity of the model. First, the methodology was applied to the same geometrical set-up as that used by the Les Renardieres Group [5], which consisted of a gap between a conical rod and a plane. The conical electrode had a tip radius of $10 \mathrm{~mm}$. The simulation was made assuming a gap distance of $2 \mathrm{~m}$ with an applied impulse peak voltage of $-1550 \mathrm{kV}$ and a $20 / 1600 \mu \mathrm{s}$ impulse waveshape.

The results of the simulations presented in Figures 6 and 7 showed that the trend exhibited by the simulated current agrees with the measured signatures determined by the Les Renardieres' Group [5]. The maximum magnitude of the current was $10 \mathrm{~A}$ for both the measurements and simulations. The simulation of the current pulsates, which is because of the restarting process and because of the exchange of charge in the channel arising from the presence of both a negative leader and a positive leader moving towards the high voltage electrode. 
Current impulses during the space stem propagation in a $2 \mathrm{~m}$ gap - conical tip.

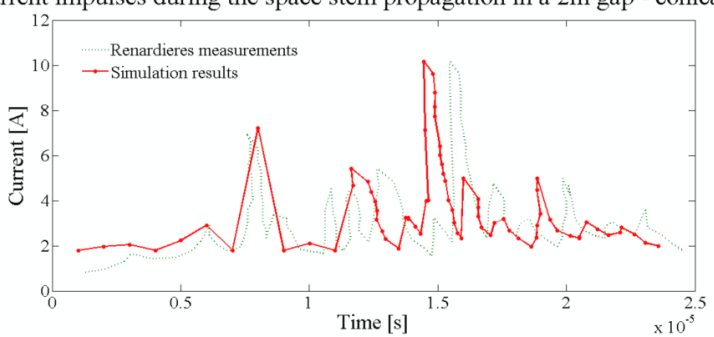

Figure 6. Current pulses during the stem-space propagation in a $2 \mathrm{~m}$ wide gap between a conical rod and

a plane with a switching impulse of $20 / 1600 \mu$ s.

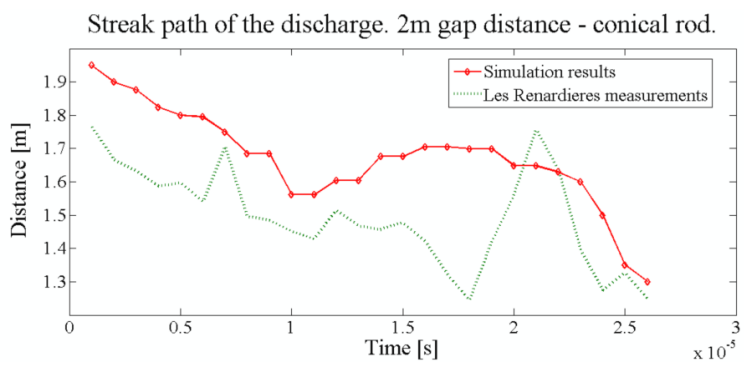

Figure 7. Streak simulated path of the discharge compared with the photographic evidence of the path extracted from the literature for a $2 \mathrm{~m}$ conical rod-plane gap during a switching impulse of $20 / 1600 \mu$ s.

Overall, the results from the model including the path of the discharge are in good agreement with the experimental results of Les Renardieres [5]. However, it is important to note that, even though the shape of the pulses correspond to those of the measurements, slight differences are evident in the timing. All pulsation behavior corresponds to the pilot streamer system representation and the initiation of pilot streamers is dependent on the exchange of positive and negative charges. It is likely, therefore, that the exchange of charges happens faster in the experiment because of external conditions in the arrangement that are not taken into account in the calculation, such as imperfections on the high voltage electrode, or external corona sources. The final parameters available for comparison are the time to breakdown and the breakdown voltage, which were calculated and are summarized in Table 2.

Table 2. Comparison between the measurements and the results of the simulation for a $20 / 1600 \mu \mathrm{s}$ impulse across a gap of $2 \mathrm{~m}$ between a conical rod and a plane.

\begin{tabular}{|c|c|c||}
\hline & $\begin{array}{c}\text { Breakdown } \\
\text { Voltage }[\mathbf{k V}]\end{array}$ & $\begin{array}{c}\text { Time to } \\
\text { Breakdown } \\
{[\boldsymbol{\mu s}]}\end{array}$ \\
\hline Les Renardieres & 1481 & 20.6 \\
\hline Simulations & 1546 & 28 \\
\hline \% error & 4.5 & 35.9 \\
\hline
\end{tabular}

The time to breakdown and the breakdown voltages exhibited errors of $35.9 \%$ and $4.5 \%$, respectively, for the particular case shown. The high error in the time to breakdown can be attributed to the path taken by the discharge. As was demonstrated by Arevalo and co-workers [22, 23], the path followed by the discharge determines the time to the breakdown, but it does not have a notable influence on the calculation of the breakdown voltage.

Owing to a lack of detailed experimental information in the literature, it is not possible to extract more parameters for the same configuration, but data for positive and negative streamer charges and for the velocity of the positive and negative leaders can be obtained from the calculation.

In another example of the usefulness of the simulation method, a rod-plane arrangement, $7 \mathrm{~m}$ gap distance, 2.8 MV peak voltage and waveform of $6 / 3000 \mu$ s configuration studied by Les Renardieres [5] was reproduced. The only available data from the configuration is the streak photograph. However, simulations of the current and the streak image are available in the literature [13]. Therefore, comparisons of our results with the published ones [13] are presented here.

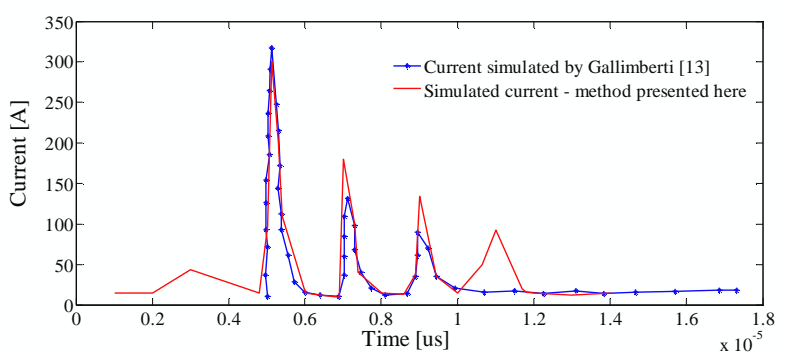

Figure 8. Computed currents of a negative discharge in a rod - plane configuration $(\mathrm{Gap}=7 \mathrm{~m}, \mathrm{Vmax}=2.8 \mathrm{MV}$, waveform $6 / 3000 \mu \mathrm{s}$ ). The continuous line corresponds to the methodology described in this paper; the line with dots corresponds to the simulation of [13] 
The simulation of the current using the methodology of this paper shows an additional peak in the current between 10 and $12 \mu \mathrm{s}$ because of the differences between the methodologies used to calculate the pilot system. However, with the exception of the aforementioned peak, one can claim that both methodologies reproduce similar peak current magnitudes and rise times. The maximum error in the current peak magnitudes is $26 \%$ for the second peak.
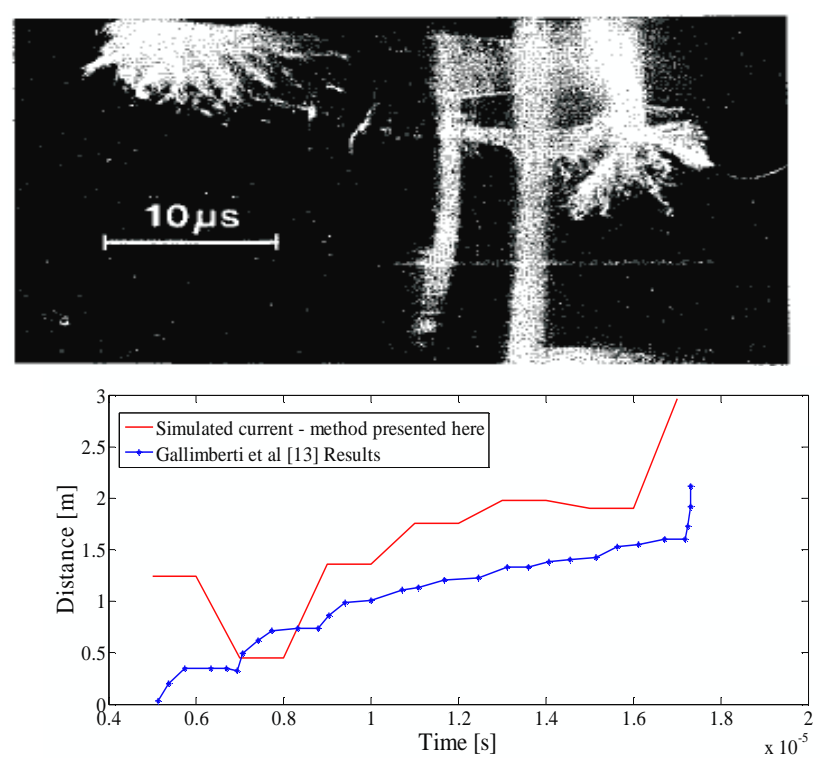

Figure 9. Computed and photographic streak image of the discharge in a rod-plane configuration $(\mathrm{Gap}=7 \mathrm{~m}$, $V \max =2.8 \mathrm{MV}$, waveform $6 / 3000 \mu \mathrm{s}$ ). The continuous line corresponds to the methodology presented in the paper; the line with dots corresponds to the simulation of [13]. The photographic image has been reproduced from [13] with copyright of Elsevier.

It is difficult to make a meaningful comparison between the photographic results and the simulation; however one can see that both simulations follow a path that apparently agrees with the photograph, and both have similar tendency.

\section{Analysis of the parameters that affect the calculation}

The proposed model includes a number of input parameters and, it is necessary to check their sensitivity on the computational procedure and to examine their variability. From all the input parameters, the ones that make the most notable change to the results are the electrical charge required to incept a negative leader, the electrical charge per unit length required to sustain the pilot progression and the electric field of the positive and negative streamer zone. Figure 10 presents the variation of the different output parameters from the calculation with respect to the current (a) and the breakdown voltage (b).

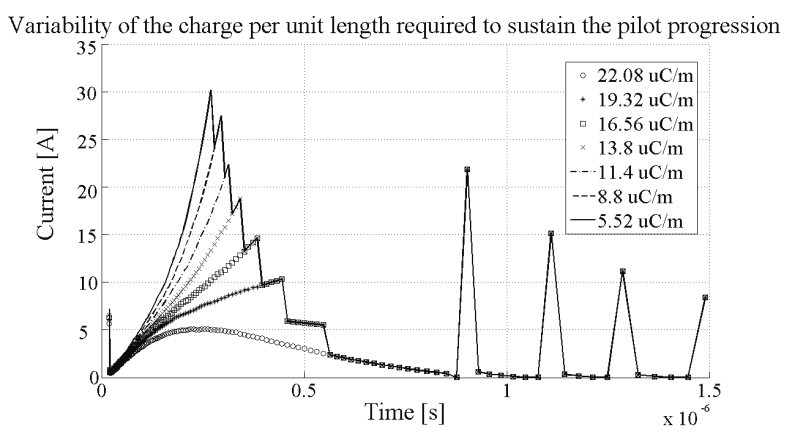

(a)

Variability of the charge per unit length required to incept a negative leader

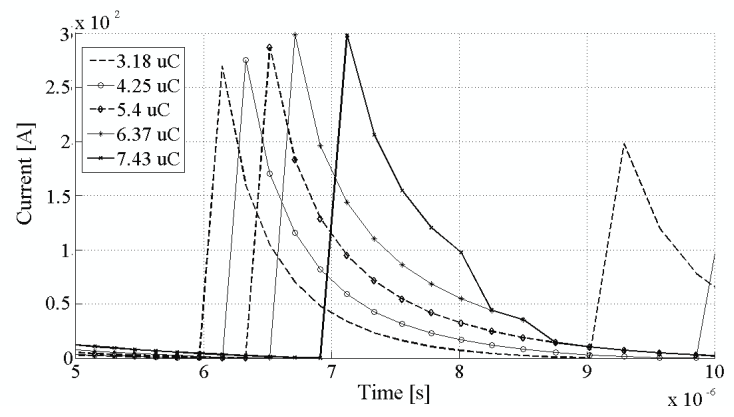

(b)

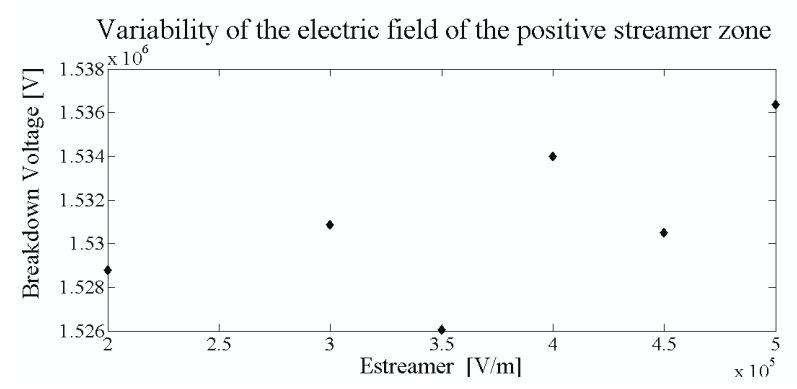

(c) 


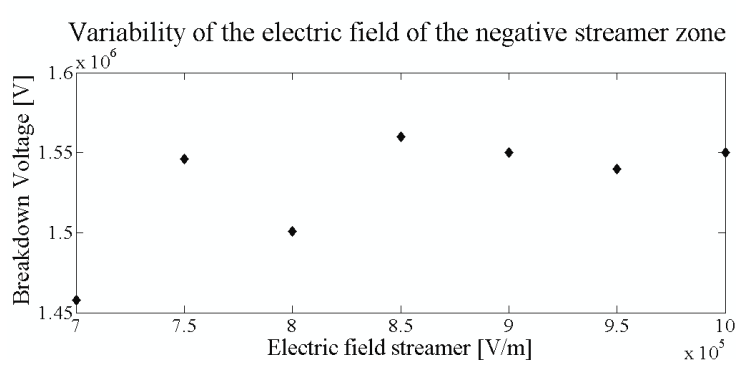

(d)

Figure 10. Variability of the input parameters: (a) the charge per unit length required to sustain the pilot progression; (b) the charge required to incept a negative leader; (c) the electric field of the positive streamer zone; and (d) the electric field of the negative streamer zone.

The charge per unit length required to sustain the pilot progression is a parameter used to calculate the advance of the pilot system in the gap space. This parameter directly affects the velocity and the current of the negative leader. The magnitude is taken from laboratory gap measurements performed by Castellani [10], since of this value was obtained for long spark gap experiments similar to the ones produced in this paper. The parameter was varied between $+60 \%$ and $-60 \%$ of the reference value taken to verify its variability, see figure 10 (a). The analysis shows that the lower the magnitude required to sustain the pilot progression, the longer the delay before the first peak of the current; the first peak occurs between 0 and $0.5 \mu \mathrm{s}$. If the parameter is changed by $60 \%$, the magnitude of the first peak current changes by $66 \%$; for moderate variations of $20 \%$ in the parameter, a change of $16 \%$ in the first peak current is observed. Other that these changes, the general trend does not change.

As far as the charge required to incept a negative leader is concerned, the lower the magnitude, the shorter the inception time of the negative leader. For example, when the parameter is increased or decreased by $20 \%$, the inception time of the negative leader changes by $\pm 3 \%$, respectively. With respect to the peak current, magnitude changes of $20 \%$ in the required charge will produce an increment in the peak current of $3.5 \%$. Therefore, one can conclude that this parameter affects the calculation, but only weakly.

According to Gallimberti [6], the potential gradient of the streamer depends on the gas pressure and water vapor content. We have taken values of between 400 and $500 \mathrm{kV} / \mathrm{m}$ for positive and 700 to $1000 \mathrm{kV} / \mathrm{m}$ for the stabilization electric field of the negative streamer. As can be seen in Figure 10 (c) and (d), the breakdown voltage is not deeply affected by this factor: variations in the breakdown voltage of less than $1 \%$ were obtained for the positive streamer and of $2 \%$ for the negative one. Consequently, for the calculation the values chosen were 450 and $750 \mathrm{kV} / \mathrm{m}$ for positive and negative streamer inception, respectively.

\section{Conclusion}

A first approximation to a self-consistent numerical simulation based on the physical process underlying the negative leader discharge has been presented here. It includes a novel way of calculating the positive streamer region for the pilot streamer system and enables the current and voltage characteristics of the complete negative discharge to be predicted. The experimental results are compared with simulations and show good agreement for the representation of the magnitudes of the current and path of the discharge.

\section{Acknowledgements}

The author would like to thank ABB/Power Systems HVDC Ludvika, Sweden for the economic support of the $\mathrm{PhD}$ candidate (L.A.).

\section{REFERENCES}

[1] Dellera, L and Garbagnati, E, 1990, Lightning stroke simulation by means of the leader progression model. Part I: Description of the model and evaluation of free-standing structures, IEEE Transaction on Power Delivery, PWRD-5. Issue 4 pp. 2009-22.

[2] Rizk F, 1994, Modeling of lightning incidence to tall structures. Part I: Theory, IEEE Trans. Power Delivery, PWRD-9, Number 1 pp. 162-171.

[3] Rizk F 1994 Modeling of lightning incidence to tall structures Part II: Applications IEEE Trans. Power Delivery, PWRD-9, Number 1, pp. 172-193.

[4] Les Renardières Group 1973 Research on long gap discharges at Les Renardières Electra $\mathbf{N} 35$.

[5] Les Renardières Group 1978 Negative discharges in long air gaps at les Renardieres. Electra WG N 33.01.

[6] Gallimberti I 1979 The mechanism of long spark formation, Journal de Physique Colloque C7, Suppl. 7, Volume 40, pp. 193-249. 
[7] Bondiou A and Gallimberti I 1994 Theoretical modelling of the development of the positive spark in long gaps, J. Phys. D 27 1252-66.

[8] Becerra, M. and V. Cooray, 2006, A self consistent upward leader propagation model, J. Phys.D: Appl. Phys. 39, pp. 3708-3715.

[9] Bacchiega G, Gazzani A, Bernardi M, Gallimberti I and Bondiou A 1994 Theoretical modelling of the laboratory negative stepped leader, Proceedings of the 1994 International Aerospace and Ground Conference on Lightning and Static Electricity, Mannheim, Germany.

[10] Castellani A., Bondiou A, Lalande P, Bonamy A and Gallimberti I, 1998, Laboratory study of the bi-leader process from an electrically floating conductor Part 2: Bileader properties. IEE Proc. Sci Meas Technol, Vol 145, No.5, September.

[11] Mazur V, Ruhnke L, Boundiou-Clergerie and Lalande P, 2000, Computer simulation of a downward negative stepped leader and its interaction with ground structures. Journal of Geophysical Research, Vol 105, No. D17, page 361 - 369. September.

[12] Lalande P, Bondiou-Clergerie A, Bacchiega G and Gallimberti I. 2002 Observations and modeling of lightning leaders. C R Physique 31375 - 92.

[13] Gallimberti I, Bacchiega G, Bondiou-Clergerie A and Lalande P 2002 Fundamental process in long air gap discharges. C R Physique 31335 - 59.

[14] Niemeyer L, Pictronero L and Wiesmann H 1984 Fractal dimension of dielectric breakdown, Phys. Rev. Lett., 52, 1033-36.

[15] Tsonis A and Eisner J 1987 Fractal characterization and simulation of lightning. Beitr. Phys Atmos 60 (2), 187-192.

[16] Sanudo J, Gomez J, Castaño F and Pacheco A 1995 Fractal dimensions of lightning discharge. Non-linear Processes in Geophysics 2, $101-106$.

[17] Petrova G 1999 Lightning stroke simulation by means of the fractal approach: Attractive and protective zones for structures, 24th International Conference on Lightning Protection, Staffordshire University, Birmingham, England.

[18] Beroual A, Rakotonandrasana J, Fofana I 2010 Predictive dynamic model of the negative lightning discharge based on the similarity with long laboratory sparks. Part 1: physical process and modeling. IEEE Transactions on Dielectrics and Electrical Insulation Vol 17, N 5, 1551 - 1561, October.

[19] Beroual A, Rakotonandrasana J, Fofana I 2010 Predictive dynamic model of the negative lightning discharge based on the similarity with long laboratory sparks. Part 2: Validation. IEEE Transactions on Dielectrics and Electrical Insulation $\mathrm{Vol} 17, \mathrm{~N} 5,1562$ - 1568, October.

[20] Arevalo L, Cooray V, Wu D and Jacobson B. A new static calculation of the streamer region for long spark gaps: numerical simulations. Journal of Electrostatics submitted for publication. March 2011.

[21] Arevalo L, Cooray V, Montano R and Roman F 2008 Modeling of positive discharges in laboratory gaps under switching impulses Gas Discharge Conference GD.

[22] Arevalo L, Cooray V and Montano R 2009 Numerical Simulation of Long Laboratory Sparks Generated by Positive Switching Impulses. Journal of Electrostatics Vol 67 Issue 2 - 3 May.
[23] Arevalo L, Cooray V and Dong W 2010 Laboratory long gaps simulation considering a variable corona region International Conference on Lightning Protection. ICLP 2010. 